\title{
Plasma hypoxanthine: a marker for hypoxic-ischaemic induced periventricular leucomalacia?
}

\author{
G A B Russell, G Jeffers, R W I Cooke
}

\begin{abstract}
Cerebral ischaemia of the immature brain may result in cavitating periventricular leucomalacia (PVL), an important association of cerebral palsy. Hypoxanthine measured by high performance liquid chromatography was used as a marker of peripartum hypoxia and ischaemia in 116 infants at risk of PVL. PVL was detected by ultrasound. The 81 infants who were unaffected had median (range) gestation of 30 weeks (24-32), weight of $1336 \mathrm{~g}$ (724-3790), and a plasma hypoxanthine concentration of $7.8 \mu \mathrm{mol} / 1(2.4-48.9)$. The seven infants who had cavitating PVL had a median gestation of 28 weeks (26-30), weight of $1165 \mathrm{~g}$ (682-1860), and a hypoxanthine concentration of $31.9 \mu \mathrm{mol} / 1$ (7.1-149). Cavitating PVL was significantly dependent only on hypoxanthine when controlling for the effects of weight and gestation. This suggests that peripartum hypoxia-ischaemia may be one of the aetiological factors in cavitating PVL. Oxidation of hypoxanthine during reperfusion generates free radicals which may contribute to the tissue destruction of PVL. The association of hypoxia-ischaemia with PVL suggests that PVL may be modified by reducing free radical activity.
\end{abstract}

Cavitating periventricular leucomalacia (PVL) is an important association of cerebral palsy and is found in $7-15 \%$ of babies under $1500 \mathrm{~g}$ at birth. ${ }^{1}$ Between $47 \%$ and $80 \%$ of infants with parenchymal cavitation develop abnormalities of neuromuscular tone and posture with or without cognitive impairment. ${ }^{2-5}$ PVL is a pathological term which has become synonymous in clinical terminology with high resolution sonographic abnormalities detected in the neonatal period ${ }^{6}$ because the parenchymal echodensities and echolucencies detected by ultrasound have been correlated with pathological abnormalities at necropsy. ${ }^{78}$ Ultrasound has led to improved understanding of the incidence, timing, and clinical associations of PVL. ${ }^{1} 910$

Risk factors associated with PVL such as prematurity, ${ }^{179}$ very low birth weight, ${ }^{19}$ antepartum haemorrhage, ${ }^{10}$ asphyxia, ${ }^{9-12}$ respiratory distress requiring mechanical ventilation, ${ }^{9-11}$ and septicaemia, ${ }^{9}$ may result in hypoxaemia and hypotension with resultant tissue hypoxia and ischaemia of the vulnerable periventricular 'watershed zones' of the immature hrain. ${ }^{13}$

The purine metabolite hypoxanthine is a marker of tissue hypoxia or ischaemia. ${ }^{14} 15$ Accumulation of hypoxanthine has been detected in cord blood from asphyxiated babies ${ }^{16-18}$ and in perfusate from ischaemic organs. ${ }^{19-21}$ The postischaemic catabolism of accumulated hypoxanthine results in the generation of tissue damaging, oxygen derived, free radicals by the action of an endothelial enzyme, xanthine oxidase, and oxygen. ${ }^{22}$ Hypoxic-ischaemic injury to the brain has been reported in animal models and tissue protection demonstrated by the administration of free radical scavengers. ${ }^{23-25}$

To test the hypothesis that an increase in hypoxanthine (as a marker of hypoxia) is associated with PVL, we have examined an 'at risk' population of preterm infants by measuring plasma hypoxanthine concentrations at birth and relating these to the subsequent development of cavitating PVL. We have assumed that cavitation represents the severest degree of ischaemic injury and therefore the severity of the hypoxic insult would be more likely to result in increased circulating hypoxanthine.

\section{Patients and methods}

Babies between 24 and 32 weeks' gestation admitted to the Regional Neonatal Intensive Care Unit were studied. Plasma hypoxanthine was measured in samples obtained from cord blood or as soon as possible after admission to the unit. Care was taken to ensure that samples were taken by large needle puncture of either cord artery or vein ${ }^{17}$ or by an indwelling arterial line or clean venesection. Samples were rapidly separated and stored at $-30^{\circ} \mathrm{C}$ to avoid leakage of erythrocyte hypoxanthine. Haemolysed samples were discarded.

Serial cranial ultrasound (ATL Ultramark 4 with a $7 \cdot 5 \mathrm{MHz}$ transducer) was performed from admission and then at least weekly until discharge. Parenchymal echodensities (of equivalent echodensity to the choroid plexus) seen in both coronal and parasagittal planes were regarded as precavitating PVL. Three groups of echolucencies were identified: porencephaly (lucency widely communicating with the ventricle), cavitating PVL (single or multiple lucencies occurring 2-3 mm from the ventricular wall), and porencephaly with associated PVL (porencephaly with surrounding noncommunicating lucencies either single or multiple occurring 2-3 $\mathrm{mm}$ from the porencephalic cavity wall).

Hypoxanthine was measured by reverse phase high performance liquid chromatography ${ }^{26}$ using a Waters model 481 LC spectrophotometer. The column $(8 \times 100 \mathrm{~mm}$ inside diameter $)$ was packed with a Nova-Pak C18 $4 \mu \mathrm{M}$ cartridge (Waters), and a Waters Guard-Pak $\mu$ Bondapak 
precolumn insert was used. The plasma samples were deproteinised by heating for 2 minutes in a boiling water bath and then ultracentrifuged for 20 minutes at $23500 \mathrm{~g}$ with a MSE Superspeed 65 centrifuge. The supernatant was diluted 1:2 with the mobile phase, $0.004 \mathrm{M}$ potassium dihydrogen orthophosphate, adjusted to $\mathrm{pH}$ $5 \cdot 8$, and injected in $20 \mu \mathrm{l}$ aliquots at a flow rate of $0.5 \mathrm{ml} / \mathrm{min}$. Detection of the eluted compounds was at $254 \mathrm{~nm}$. The effluent peaks were identified by their retention times determined by known standards and confirmed by enzymic digestion using xanthine oxidase (Merck). Activity of xanthine oxidase: 0.4 enzyme unit (EU)/mg protein with hypoxanthine as substrate and $0.8 \mathrm{EU} / \mathrm{mg}$ protein with xanthine as substrate). Quantification of the peaks was computed from standard pure compound peaks before and after each 6-8 sample injections. The standards (hypoxanthine and xanthine) were supplied by Merck.

The assay had a recovery of $>95 \%$ of known concentrations of hypoxanthine from $5 \mu \mathrm{mol} / 1$ to $100 \mu \mathrm{mol} / \mathrm{l}$ and the coefficient of variation

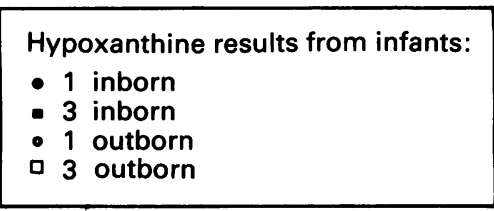

$142 \cdot 9 \bullet$

$108.9 \bullet$

- 68

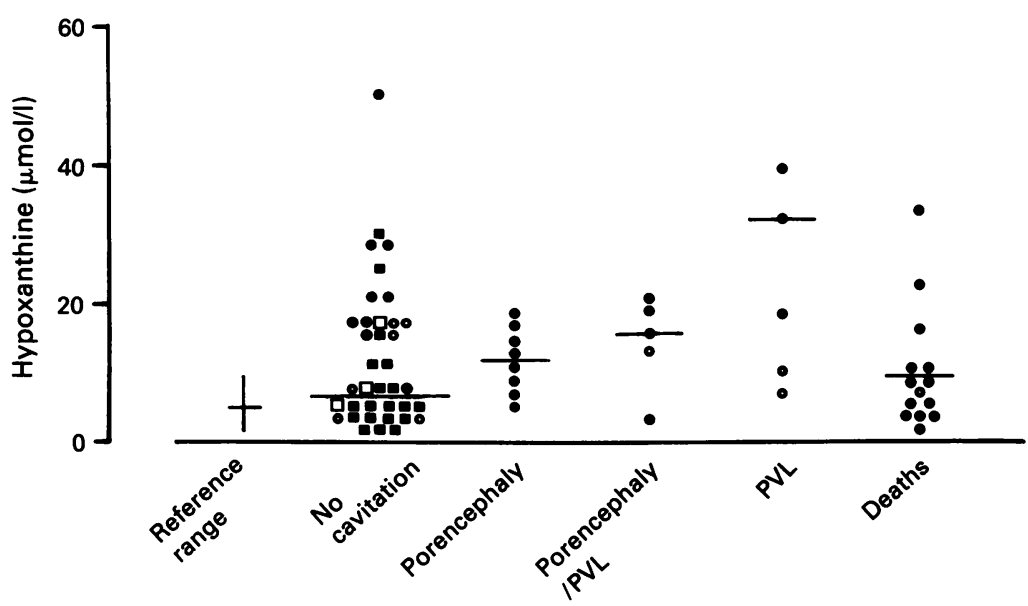

Plot of plasma hypoxanthine concentration in 116 preterm babies. Horizontal bars indicate the median value for each group. The reference range indicated on the left is the mean ( $2 S D)$ of cord plasma hypoxanthine of a group of 22 term babies delivered by elective caesarean section.

Table 1 Details of preterm infants examined by cerebral ultrasound after postpartum plasma hypoxanthine sampling

\begin{tabular}{|c|c|c|c|c|}
\hline & $\begin{array}{l}\text { No cavitation } \\
(n=81)\end{array}$ & $\begin{array}{l}\text { Porencephaly } \\
(n=8)\end{array}$ & $\begin{array}{l}\text { Porencephaly/ } \\
\text { PVL }(n=5)\end{array}$ & $\begin{array}{l}P V L \\
(n=7)\end{array}$ \\
\hline $\begin{array}{l}\text { Gestation (weeks): } \\
\text { Median } \\
\text { Range }\end{array}$ & $\begin{array}{l}30 \\
24-32\end{array}$ & $\begin{array}{l}28^{*} \\
26-31\end{array}$ & $\begin{array}{l}27^{*} \\
27-29\end{array}$ & $\begin{array}{l}28^{*} \\
26-30\end{array}$ \\
\hline $\begin{array}{l}\text { Weight (g): } \\
\text { Median } \\
\text { Range }\end{array}$ & $\begin{array}{l}1336 \\
724-3790\end{array}$ & $\begin{array}{l}1135 \\
682-1860\end{array}$ & $\begin{array}{l}850^{*} \\
758-1432\end{array}$ & $\begin{array}{l}1165 \\
682-1860\end{array}$ \\
\hline $\begin{array}{l}\text { Hypoxanthine }(\mu \mathrm{mol} / \mathrm{l}) \text { : } \\
\text { Median } \\
\text { Range }\end{array}$ & $\begin{array}{l}7 \cdot 8 \\
2 \cdot 4-48 \cdot 9\end{array}$ & $\begin{array}{l}12 \cdot 3 \\
7 \cdot 4-18 \cdot 4\end{array}$ & $\begin{array}{l}14 \cdot 7 \\
2 \cdot 9-19 \cdot 4\end{array}$ & $\begin{array}{l}31 \cdot 9 * * \\
7 \cdot 1-142 \cdot 9\end{array}$ \\
\hline $\begin{array}{l}\text { Sample time (min): } \\
\text { Median } \\
\text { Range }\end{array}$ & $\begin{array}{l}100 \\
0-972\end{array}$ & $\begin{array}{l}107 \\
0-308\end{array}$ & $\begin{array}{l}85 \\
0-566\end{array}$ & $\begin{array}{l}76 \\
0-588\end{array}$ \\
\hline
\end{tabular}

Compared with non-cavitation group: ${ }^{*} \mathrm{p}<0 \cdot 05 ;{ }^{* *} \mathrm{p}<0.005(95 \%$ CI $4 \cdot 0$ to $81 \cdot 0)$. was $5 \cdot 6 \%$. Results of hypoxanthine were not available until 6-8 weeks after birth and this avoided observer bias in the diagnosis of PVL. The reference plasma hypoxanthine concentration in our unit was $4.7 \mu \mathrm{mol} / \mathrm{l}$ (95\% confidence interval (CI) $3 \cdot 7$ to $5 \cdot 7$ ) with the upper limit (2 SD) of $9.5 \mu \mathrm{mol} / 1$ determined from cord arterial blood obtained from 22 unstressed term infants delivered at elective caesarean section (figure).

Statistical analysis was by Mann-Whitney U test for comparison of non-parametric data, and multiple logistic regression analysis was used to control for confounding variables when dichotomous outcome variables were evaluated. The SPSS-X $3 \cdot 1$ statistical package on an IBM 3081 mainframe computer was used.

Informed parental consent was obtained for all patients studied and ethical approval was granted by the hospital ethical committee for the study.

\section{Results}

Of the 116 babies studied, 15 died within 14 days without developing cavitating PVL (four had echodensities). Of the 101 survivors, 81 did not develop parenchymal cavitation but four of them had parenchymal echodensities which resolved. The remaining $20(17 \cdot 2 \%)$ babies developed parenchymal cavitation: seven of these had cavitating PVL alone, eight had porencephaly alone, and five had porencephaly with associated PVL.

The two groups with porencephaly, with or without PVL, had higher median hypoxanthine concentrations than the unaffected group but the differences were not significant (table 1). The group with PVL alone had a median hypoxanthine which was significantly higher at $31.9 \mu \mathrm{mol} / 1(\mathrm{p}<0.005)$. This difference persisted after adjusting for gestation and weight $(p<0.05)$ by multiple logistic regression, with PVL as the dependent variable, and weight, gestation, and hypoxanthine as the independent variables. A measure of the risk of developing PVL, the odds ratio (OR), was calculated from the regression model. The OR (with $95 \% \mathrm{CI}$ ) for developing PVL was $1.89(1.01$ to 3.53$)$ for every $10 \mu \mathrm{mol} / \mathrm{i}$ increase of hypoxanthine $(p<0.05)$. The unit change of the independent variable is arbitrarily selected for convenience, such as one week for gestation or $10 \mu \mathrm{mol} / 1$ for hypoxanthine.

No significant dependence on hypoxanthine (while controlling for weight and gestation) could be demonstrated for porencephaly alone (OR $0.75 ; 95 \%$ CI 0.43 to 1.85 ) or porencephaly with associated PVL (OR 1.52; 95\% CI 0.97 to $2 \cdot 38)$.

The details of babies who developed parenchymal cavitation, including the time delay in sampling of blood for hypoxanthine, are shown in table 2 and the figure demonstrates the plot of hypoxanthine concentrations for each group. An increased concentration of hypoxanthine within two hours of birth, thought to indicate antenatal hypoxia, ${ }^{16} 27$ was found in all three groups of parenchymal cavitation: $4 / 7$ of the group with PVL, 4/8 of the porencephaly group, and 3/5 of the porencephaly and associ- 
Table 2 Details of patients with parenchymal cavitation

\begin{tabular}{|c|c|c|c|c|c|c|}
\hline $\begin{array}{l}\text { Case } \\
\text { No }\end{array}$ & $\begin{array}{l}\text { Gestation } \\
\text { (weeks) }\end{array}$ & $\begin{array}{l}\text { Weight } \\
(g)\end{array}$ & Sex & Birth & $\underset{(\text { min })}{\text { Sample time }}$ & $\begin{array}{l}\text { Hypoxanthine } \\
\text { (ןlimol/l) }\end{array}$ \\
\hline $\begin{array}{c}\text { PVL } a l \\
1 \\
2 \\
3 \\
4 \\
5 \\
6 \\
7 \\
7 \\
\text { Median }\end{array}$ & $\begin{array}{l}30 \\
26 \\
27 \\
28 \\
26 \\
29 \\
28 \\
28\end{array}$ & $\begin{array}{r}1420 \\
726 \\
682 \\
998 \\
1220 \\
1860 \\
1165 \\
1165\end{array}$ & $\begin{array}{l}M \\
F \\
F \\
M \\
M \\
M \\
M\end{array}$ & $\begin{array}{l}\text { Inborn } \\
\text { Inborn } \\
\text { Inborn } \\
\text { Inborn } \\
\text { Outborn } \\
\text { Outborn } \\
\text { Outborn }\end{array}$ & $\begin{array}{l}76 \\
\text { Cord } \\
\text { Cord } \\
\text { Cord } \\
420 \\
290 \\
558 \\
76\end{array}$ & $\begin{array}{r}39.0 \\
18.0 \\
31.9 \\
108.9 \\
142.9 \\
9.5 \\
7.1 \\
31.9\end{array}$ \\
\hline $\begin{array}{c}\text { Porence } \\
13 \\
14 \\
15 \\
16 \\
17 \\
18 \\
19 \\
20 \\
\text { Median }\end{array}$ & $\begin{array}{c}\text { alone } \\
28 \\
28 \\
29 \\
26 \\
28 \\
27 \\
31 \\
31 \\
28\end{array}$ & $\begin{array}{r}1150 \\
1120 \\
1382 \\
762 \\
1072 \\
1082 \\
1588 \\
1616 \\
1135\end{array}$ & $\begin{array}{l}\mathbf{M} \\
\mathbf{M} \\
\mathbf{M} \\
\mathbf{M} \\
\mathbf{M} \\
\mathbf{M} \\
\mathbf{F} \\
\mathbf{M}\end{array}$ & $\begin{array}{l}\text { Inborn } \\
\text { Inborn } \\
\text { Inborn } \\
\text { Inborn } \\
\text { Inborn } \\
\text { Inborn } \\
\text { Inborn } \\
\text { Inborn }\end{array}$ & $\begin{array}{l}90 \\
84 \\
120 \\
150 \\
308 \\
170 \\
\text { Cord } \\
\text { Cord } \\
107\end{array}$ & $\begin{array}{r}11 \cdot 4 \\
14 \cdot 3 \\
16 \cdot 6 \\
8 \cdot 0 \\
7 \cdot 7 \\
18 \cdot 4 \\
7 \cdot 4 \\
13 \cdot 2 \\
12 \cdot 3\end{array}$ \\
\hline $\begin{array}{c}\text { Porence } \\
8 \\
9 \\
10 \\
11 \\
12 \\
\text { Median }\end{array}$ & $\begin{aligned} \text { and } P V L \\
27 \\
27 \\
27 \\
28 \\
27 \\
27\end{aligned}$ & $\begin{array}{r}758 \\
900 \\
812 \\
1220 \\
1432 \\
900\end{array}$ & $\begin{array}{l}M \\
F \\
F \\
F \\
M\end{array}$ & $\begin{array}{l}\text { Inborn } \\
\text { Inborn } \\
\text { Inborn } \\
\text { Inborn } \\
\text { Outborn }\end{array}$ & $\begin{array}{c}\text { Cord } \\
85 \\
85 \\
\text { Cord } \\
566 \\
85\end{array}$ & $\begin{array}{r}19 \cdot 4 \\
14 \cdot 7 \\
18 \cdot 9 \\
2 \cdot 9 \\
12 \cdot 7 \\
14 \cdot 7\end{array}$ \\
\hline
\end{tabular}

ated PVL group. An increase in hypoxanthine within two hours of birth was also found in 20/43 babies in the non-cavitating group.

In some of the babies, an increased concentration was found at later sampling times and may have been due to postnatal events, although all patients received intensive care support throughout the period from delivery to sampling to minimise hypoxia or ischaemia. The delay in sampling was due to either postnatal transfer (4/20 with parenchymal cavitation or $21 / 81$ with no cavitation) or the delay in gaining vascular access for blood sampling if cord blood was not available. No significant differences in sampling time were detected between the groups with cavitation and the group with no cavitation. Although there was a trend to lower concentrations of hypoxanthine with increasing time delay to sampling this was not significant (Spearman correlation coefficient $=-0 \cdot 1295$; $p>0 \cdot 1)$, and this suggests that the normal concentrations of hypoxanthine in the noncavitation group was not merely due to delay in sampling after delivery.

The group of 15 babies who died had a median (range) gestation of 27 weeks (24-31) and weight of $850 \mathrm{~g}$ (565-1260). In this group the median hypoxanthine was $8.6 \mu \mathrm{mol} / \mathrm{l}(2.4$ $68 \cdot 3)$ and the sampling time was $78 \mathrm{~min}$ (0-380) (see figure).

\section{Discussion}

Events such as antepartum haemorrhage and clinical perinatal asphyxia have been associated with subsequent development of PVL, ${ }^{9-12}$ and parenchymal echodensities detected by ultrasound may appear within three days of birth, ${ }^{1}$ suggesting that many cases are related to peripartum events. PVL is a manifestation of cerebral hypoxia-ischaemia, ${ }^{28}$ and an increased concentration of plasma hypoxanthine is a biochemical marker of peripartum hypoxia. ${ }^{16-18}$ The association we have found between increased early plasma hypoxanthine and the develop- ment of PVL gives indirect evidence to support the hypothesis that cerebral hypoxia-ischaemia may induced PVL in preterm infants.

There is conflicting evidence for an association between increased concentrations of plasma hypoxanthine and adverse clinical outcome in term babies. Increased cord hypoxanthine or hypoxanthine excretion is found in asphyxiated babies with a reduced 'optimality score'16 or abnormal neurological signs during the first week of life but there is considerable overlap with unaffected babies. ${ }^{16} 18$ Neurological assessment at 2 years could not be correlated with cord hypoxanthine in term babies ${ }^{29}$ but we are not aware of any evidence for preterm babies. The fetal cerebral oxygen uptake rapidly decreases with falling arterial oxygen saturation, especially in combination with acidaemia, ${ }^{30}$ and so the effect of global hypoxaemia on the vulnerable periventricular watershed zones could affect the fetal and preterm brain more than the term infant with more developed periventricular anastamoses. ${ }^{13}$

Our study may have underestimated any association between increased plasma hypoxanthine and PVL because delay in sampling (including outborn babies) was unavoidable in many babies and also because subsequent postnatal hypoxic-ischaemic insults after the admission sampling would not have been detected by hypoxanthine measurements: any increase due to birth asphyxia might have returned to normal giving a false negative association with PVL. On the other hand normal concentrations detected in babies without PVL might have been due to delayed sampling. We found no correlation between sample time and hypoxanthine concentration and this suggests that in the noncavitating group the normal value of hypoxanthine was not due to delayed sampling. The half life of plasma hypoxanthine is three minutes in rabbits ${ }^{31}$ and 40 minutes in pigs after a hypoxic-ischaemic episode ${ }^{32}$; in term babies increased concentrations may be detected for two hours after asphyxia ${ }^{1627}$ and in preterm babies increased values have persisted for 24 hours after an hypoxic episode. ${ }^{14}$ Plasma hypoxanthine is likely to be trapped in tissues because of inadequate tissue perfusion and circulation; increased values may therefore be detected for some time after the hypoxic insult, until adequate circulation is re-established. This may explain the marked increase in hypoxanthine $(142.9 \mu \mathrm{mol} / \mathrm{l})$ at seven hours in one baby in the PVL group, despite establishing adequate oxygenation and blood pressure after an emergency caesarean section for footling breech presentation (table 2 , case 5 ).

The degree and timing of the hypoxic episode would influence the magnitude and duration of hypoxanthine increases. An insult occurring in the peripartum period may not therefore have been detected by admission sampling of outborn babies at six to eight hours. Two of the lowest values of hypoxanthine in the PVL group were recorded from outborn infants. About half of the babies from our study who developed any form of parenchymal cavitation had evidence of birth asphyxia, evidenced by increased concentrations of hypoxanthine (greater than $2 \mathrm{SD}$ 
from the mean: $9 \cdot 5 \mu \mathrm{mol} / \mathrm{l}$ ) within two hours of birth. This would suggest that the hypoxicischaemic insult occurring antenatally might be associated with later development of parenchymal cavitation.

Increased hypoxanthine has been detected after postnatal events such as pneumothorax, mechanical ventilation for severe respiratory distress syndrome, shock, and necrotising enterocolitis (own observations). Global hypoxia increases plasma hypoxanthine (probably arising from organs with a lower threshold for purine degradation, such as the liver and gut) whereas focal ischaemia within an organ, especially the brain with a higher threshold for purine degradation, may not increase systemic plasma hypoxanthine sufficiently to be detectable by remote sampling. ${ }^{33}$ Plasma hypoxanthine measured in peripheral plasma is therefore a marker of global hypoxia but this is likely to be associated with global cerebral hypoxiaischaemia. Cerebral hypoxia and ischaemia may therefore be a mechanism of parenchymal injury in pneumothorax, severe respiratory distress requiring mechanical ventilation and shock.

In our study, plasma hypoxanthine was only slightly increased in the two groups in which porencephaly was found. This could be because early sampling did not detect a later postnatal event or because porencephaly may result from different pathogenic mechanisms. First, localised parenchymal infarction secondary to the presence of a contiguous large blood clot and release of vasoactive substances such as thromboxane, prostacyclin, ${ }^{34}$ or potassium ${ }^{35}$ may lead to porencephaly rather than PVL. Second, parenchymal venous infarction due to obstruction of veins of the periventricular white matter by distension of the germinal matrix and ventricles after periventricular haemorrhage, could also cause porencephaly and possibly PVL. ${ }^{36}$ PVL associated with porencephaly is likely to be secondary to the pathogenic mechanisms responsible for porencephaly. Not all cases of PVL occur in association with periventricular haemorrhage and it is therefore likely that PVL is due to local or generalised cerebral ischaemic infarction, and porencephaly due to local ischaemia or venous infarction. Unfortunately sampling of plasma hypoxanthine from the cerebral venous drainage is not possible in premature babies, and therefore it is difficult to detect direct evidence of local or even global cerebral ischaemia based on hypoxanthine concentrations. Cerebral arteriovenous hypoxanthine difference increases significantly during severe asphyxia in the fetal lamb brain, even though there is a high threshold for degrading energy rich intracellular purines. ${ }^{33}$

Hypoxanthine is also a free radical generator ${ }^{37}$ and this recognition has resulted in renewed interest in the hypoxic-ischaemic mechanism of tissue injury. Free radical induced tissue damage has been demonstrated secondary to excessive production of free radicals by the xanthine oxidase-hypoxanthine reaction. ${ }^{22}$ If hypoxiaischaemia and free radical generation are aetiological factors in ischaemic disorders of the infant brain, this suggests possible strategies for intervention. Prophylactic inhibition of xanthine oxidase in preterm babies at risk of PVL may reduce the free radical generation after reperfusion/reoxygenation and may therefore limit the extent of tissue destruction. Allopurinol and its major active metabolite oxypurinol are specific inhibitors of xanthine oxidase that have been shown to limit tissue damage due to free radical activity. ${ }^{23} 24$ Other free radical scavengers may also have a place in ameliorating damage. ${ }^{25}$ Difficulties would be encountered in antenatal hypoxia, but peripartum and postpartum hypoxic-ischaemic insults may be more amenable to therapeutic intervention.

1 Trounce JQ, Rutter N, Levene MI. Periventricular leucomalacia and intraventricular haemorrhage in the preterm neonate. Arch Dis Child 1986;61:1196-202.

2 Fawer C-L, Calame A, Furrer M-T. Neurodevelopmental outcome at 12 months of age related to cerebral ultrasound appearances of high risk preterm neonates. Early Hum Dev 1985;11:123-32.

3 Graham M, Levene MI, Trounce JQ, et al. Prediction of cerebral palsy in VLBW infants: prospective ultrasound study. Lancet 1987; ii:593-5.

4 Fawer CL, Diebold P, Calame A. PVL and neurodevelopmental outcome in preterm infants. Arch Dis Child mental outco

5 Stewart AL, Reynolds EOR, Hope PL, et al. Probability of neurodevelopmental disorders estimated for US appearance of brains of very preterm infants. Dev Med Child Neurol 1987;29:3-11.

6 Leviton A, Paneth N. White matter damage in preterm newborns - an epidemiologic perspective. Early Hum Dev 1990;24:1-22.

7 Hill A, Melson GL, Clark HB, Volpe JJ. Hemorrhagic periventricular leukomalacia: diagnosis by real time ultrasound and correlation with autopsy findings. Pediatrics 1982;69:282-4

8 Trounce JQ, Fagan D, Levene MI. Intraventricular haemorrhage and periventricular leucomalacia: ultrasound and autopsy correlation. Arch Dis Child 1986;61:1203-7.

9 Sinha SK, Davies JM, Sims DG, Chiswick ML. Relation between periventricular haemorrhage and ischaemic brain lesions diagnosed by ultrasound in very pre-term infants. Lancet 1985;ii:1154-5.

10 Weindling AM, Rochefort MJ, Calvert SA, Fok T-F Wilkinson A. Development of cerebral palsy after ultrasonographic detection of periventricular cysts in the newborn. Dev Med Child Neurol 1985;27:800-6.

11 De Vries LS, Regev R, Dubowitz MS, Whitelaw A, Aber VR. Perinatal risk factors for the development of extensive cystic leukomalacia. Am $\mathcal{F}$ Dis Child 1988;142:732-5.

12 Trounce JQ, Shaw DE, Levene MI, Rutter N. Clinical risk factors and periventricular leucomalacia. Arch Dis Child 1988;63:17-22.

13 De Reuk JL. Cerebral angioarchitecture and perinatal brain lesions in premature and full-term infants. Acta Neurol Scand 1984;70:391-5.

14 Saugstad OD. Hypoxanthine as a measurement of hypoxia. Pediatr Res 1975;9:158-61.

15 Saugstad OD. Hypoxanthine as an indicator of hypoxia: its role in health and disease through free radical production. Pediatr Res 1988;23:143-50.

16 Thiringer $\mathrm{K}$. Cord plasma hypoxanthine as a measure of foetal asphyxia. Acta Paediatr Scand 1983;72:231-7.

17 Bratteby L-E, Swanström S. Hypoxanthine concentration in plasma during the first two hours after birth in normal and plasma during the first two hours after birth in n
asphyxiated infants. Pediatr Res 1982;16:152-5.

18 Harkness RA, Whitelaw AGL, Simmonds RJ. Intrapartum hypoxia: the association between neurological assessment of hypoxia: the association between neurological assessment of damage and abnormal excretion

19 Saugstad OD, Schrader H. The determination of inosine and hypoxanthine in rat brain during normothermic and hypothermic anoxia. Acta Neurol Scand 1978;57:281-8.

20 Buhl MR, Jorgensen S. Breakdown of 5 '-adenine nucleotide in ischemic renal cortex estimated by oxypurine excretion during perfusion. Scand $\mathcal{F}$ Clin Lab Invest 1975;35:211-7.

21 Berne RM, Rubio R. Adenine nucleotide metabolism of the heart. Circ Res 34/35 (Suppl) 1974;111:109-20.

22 Zweier JL, Kuppusamy P, Lutty GA. Measurement of endothelial cell free radical generation: evidence for a central mechanism of free radical injury in postischemic central mechanism of free radical injury in postis
tissues. Proc Natl Acad Sci USA 1988;85:4046-50.

23 Martz D, Rayos G, Schielke GP, Betz AL. Allopurinol and dimethylthiourea reduce brain infarction following middle

24 Palmer C, Vannucci RC, Towfighi J. Reduction of perinatal hypoxic-ischemic brain damage with allopurinol. Pediatr hypoxic-ischemic b
Res 1990;27:332-6.

25 Pourcyrous M, Leffler CW, Mirro R, Busija DW. Brain superoxide generation during asphyxia and reventilation in superoxide generation during asphyxia and
newborn pigs. Pediatr Res 1990;28:618-21.

26 Boulieu R, Bory C, Baltassat P. High-performance liquid 
chromatographic determination of hypoxanthine and xanthine in biological fluids. I Chromatogr 1982;233: xanthine

27 Swanström S, Bratteby L-E. Hypoxanthine as a test of perinatal hypoxia as compared to lactate, base deficit, and perinatal hypoxia as compared to

28 Banker BQ, Larroche-J-C. Periventricular leukomalacia of infancy. Arch Neurol 1962;7:386-410.

29 Ruth V, Autti-Rämö I, Granström M-L, Korkman M, Raivio KO. Prediction of perinatal brain damage by cord plasma vasopressin, erythropoietin, and hypoxanthine values. J Pediatr 1988;113:880-5

30 Kjellmer I, Karlsson K, Olsson T, Rosén KG. Cerebral reactions during intrauterine asphyxia in the sheep. 1. Circulation and oxygen consumption in the fetal brain. Pediatr Res 1974;8:50-7.

31 Spector R. Hypoxanthine transport and metabolism in the central nervous system. 7 Neurochem 1988;50:969-78.

32 Saugstad OD, Aasen AO, Hetland O. Plasma hypoxanthine levels in pigs during acute hypor between lactate and base deficit concentrations. Eur Surg Res 1978;10:314-21.

33 Thiringer K, Blomstrand S, Hrbek A, Karlsson K, Kjellmer I. Cerebral arterio-venous difference for hypoxanthine and lactate during graded asphyxia in the fetal lamb. Brain Res lactate during graded

34 Rennie JM, Doyle J, Cooke RWI. Elevated levels of immunoreactive prostacyclin metabolite in babies who immunoreactive prostacyclin metabolite in babies who develop intravent

35 Edvinsson L, Lou HC, Tvede K. On the pathogenesis of regional cerebral ischaemia in intracranial haemorrhage: a 1986;20:478-80.

36 Gould SJ, Howard S, Hope PL, Reynolds EOR. Periventricular intraparenchymal cerebral haemorrhage in preterm infants; the role of venous infarction. $\mathcal{F}$ Pathol 1987;151:197-202.

37 Granger DN, Höllwarth ME, Parks DA. Ischemia-reperfusion injury: role of oxygen-derived free radicals. Acta Physiol Scand 1986;548:suppl:47-63. 